\title{
Presentation of a new section in RC\&SC
}

As part of the reflections on its twenty years of existence, Ciência \& Saúde Coletiva shall publish the series Construtores da Saúde Coletiva [Collective Health Builders] throughout 2015. The objective is to publish a set of articles on individuals/actors who have contributed decisively, with ideas and actions, to the construction of the field of collective health within Brazil. The review will publish at least one (1) article in each of the 2015 issues. In this way, Ciência \& Saúde Coletiva will virtuously follow permanent section initiatives on the history of the field of health, which have long been present in prestigious periodicals, such as the American Journal of Public Health with its "Voices from the Past". We start from the assumption that collective health was constructed historically by a number of individuals, groups and institutions in various areas of knowledge and professional practice, located both within Brazil and outside it. We also understand that this was historically a polyphonic and polysemic process which, for this very reason, embarrasses monopolies, whether interpretive, institutional or political. This understanding must today encourage debate on the present and future of health of Brazil's population.

Construtores da Saúde Coletiva [Collective Health Builders] were men and women who, in different ways, thought, wrote, spoke, acted, organized, administered and essentially desired and imagined institutions, associations, policies and health systems which were more public, national, inclusive and egalitarian. Imagination and practices which were contaminated by contradictions, conflicts and profound differences regarding the paths to be followed, at different times and in different places. The very terminologies which identified the field form a part of this process: hygiene, public health, preventive medicine, social medicine, collective health. These were legacies and choices located in space and time. The possible consensuses were certainly fruits of this historical and political construction named collective health, the effects of which could not be anticipated by those who had been reflecting and acting on the situation of Brazilian health since the middle of the twentieth century.

This series will encourage temporal, ideological, institutional, professional, organisational and geographical diversity. International personalities/actors, especially Latin American ones, who influenced Brazilian collective health, shall be considered. Every choice is dramatic and incomplete, but we believe that an initial selection should be a consistent point of departure for the recovery of the most recent trajectory in the field and of its different voices, starting from a set of biographical profiles and that new names must be suggested and incorporated. This is not a case of ratifying or creating a pantheon. On the contrary, we must indeed celebrate our builders, albeit while locating them critically in their time, in history. We also intend to highlight individuals who are less visible, some effectively forgotten, in the more established narratives on health reform and on the creation of the Brazilian Unified National Health System (SUS). As a milestone in time, we shall give priority to individuals whose actions were more salient, starting from the end of the Second World War, in particular, from 1964 onwards, the year of the military coup which ended the democratic experience, inaugurated in 1945.

Each article, which shall be peer-reviewed, shall, at the same time, be a profile and a critical balance sheet of the professional and political trajectory and ideas of each of the builders. It shall consider biographical information, intellectual output, whether academic, in the media, teaching material, speeches, interviews and communication with the general public, and also professional, associative and political activities. Following Pierre Bourdieu's warning, we shall not deceive ourselves with the biographies but bet on them as one of the possibilities for understanding the construction of collective health as an intellectual, professional and institutional field. The balance between a political, intellectual and professional trajectory is certainly a challenge, given the limits of a scientific article. The aim is not, however, to deal with the overall dimension of the individual and his or her works and ideas but with the aspects that were most significant and which had the greatest impact on collective health, within the health system and in the health reform.

Lastly, the publishers of the series invite authors and readers to know more critically our history and to pay tribute to those individuals who helped to imagine and build the collective health as well as Brazil.

Gilberto Hochman

Everardo Duarte Nunes

Guest Editors 